\title{
PENGARUH PENERAPAN SISTEM INFORMASI AKUTANSI TERHADAP KINERJA KARYAWAN BRI CABANG BANDA ACEH
}

\author{
Dico Wiranto ${ }^{1}$, Muslim ${ }^{* 2}$ \\ ${ }^{1,2}$ Program Studi Akuntansi Fakultas Ekonomi Universitas Syiah Kuala \\ e-mail: dicowiranto16@gmail.com ${ }^{1}$, muslimadjalil@ unsyiah.ac.id ${ }^{* 2}$
}

\section{* Corresponding Author}

\begin{abstract}
The problem in this study is whether How Accounting Information Systems affect Employee Performance. The purpose of this study was to determine the effect of the effect of Accounting Information Systems on Employee Performance. The location of the study is at PT Bank BRI Banda Aceh, the number of respondents is 105 customers, while the sampling technique uses Non Probability Sampling where researchers accidentally meet with the Employee, the technique of collecting data is a questionnaire, data analysis is calculated with the help of SPSS 19.0 with qualitative analysis tools and quantitatively and using a simple regression analysis hypothesis test. From the results of the research and discussion of the analysis of the results that have been carried out in this study, it can be concluded that the Accounting Information System has a positive effect on Employee Performance at the BRI Branch and the Banda Aceh Region. It can be said that accounting information systems are very helpful for a number of employee jobs, and SIA at Bank BRI is currently quite good at measuring performance. It has been proven in this study that AIS assesses that employee performance can be assessed from a program.
\end{abstract}

Keywords: Accounting Information Systems, Employee Performance

\section{Pendahuluan}

Perkembangan teknologi yang terjadi di bidang bisnis sangatlah pesat. Baru-baru ini, tujuan dari organisasi telah bergeser dari era dulu yang hanya memikirkan suatu keuntungan dan kelangsungan hidup seseorang. Saat ini, tujuan dari organisasi dan lembaga keuangan berada jauh lebih baik dari era dulu yang hanya bertujuan untuk keuntungan, tetapi pada era globalisasi memperoleh keuntungan bukan prioritas utama, prioritas utama saat ini adalah kepuasan pelanggan yang kompetitif dan pengambilan keputusan yang efektif. Dalam mencapai tujuan organisasi, salah satunya adalah teknologi. Teknologi sangat penting dalam lembaga keuangan atau Bank, sistem itu disebut Sistem Informasi Akuntansi (SIA). SIA berisi serangkaian perangkat yang digunakan untuk melakukan satu set fungsi bisnis umum seperti akuntansi, manajemen sumber daya manusia dan manajemen operasional. Sifat inti dari sebuah SIA untuk komputerisasi proses bisnis dan yang paling penting, untuk menghasilkan data secara real-time.

Saira et al (2010) menyatakan bahwa Sistem Informasi Akuntansi bertanggung jawab untuk menganalisa dan memantau kondisi keuangan perusahaan, persiapan dokumen yang diperlukan untuk tujuan pajak, dan memberikan informasi untuk mendukung banyak fungsi organisasi lainnya seperti produksi, pemasaran, manajemen sumber daya manusia, serta perencanaan strategis. Selanjutnya, Ferran dan Salim (2011) berpendapat bahwa, dengan pengguna aplikasi Informasi Teknologi (IT), atau stakeholder dapat diberikan akses ke informasi akuntansi mereka agar jauh lebih mudah dan rinci, bukan hanya berupa laporan keuangan. SIA adalah informasi akuntansi otomatis yang bergantung pada perangkat lunak komputer dan sistem informasi akuntansi untuk menangkap dan memproses data akuntansi dalam organisasi.

Sistem informasi memiliki peranan yang sangat penting dalam sebuah bidang akuntansi, karena umummnya tujuan utama akuntansi adalah untuk menciptakan informasi pada para pengambil keputusan. Perkembangan perekonomian di Indonesia yang semakin maju, memaksa bank-bank untuk menawarkan berbagai fasilitas layanan perbankan Indonesia. Secara tujuannya semua Bank akan selalu 
mengutamakan informasi untuk mengambil keputusan. Informasi yang dibutuhkan haruslah informasi yang akurat, yang tersedia tepat waktu kapanpun dibutuhkan, dan memiliki nilai yang tepat dan relevan. Informasi-informasi ini pada dasarnya dihasilkan oleh suatu sistem informasi yang berbasis sistem komputer.

Pada saat ini kinerja perbankan di Indonesia mengalami penurunan hal itu dapat dilihat dari Utang Luar Negeri (ULN) pada akhir triwulan I 2017 berada pada posisi USD326,3 miliar tumbuh sebesar 2,9\% atau sedikit meningkat dibanding triwulan sebelumnya yang sebesar 2,0\%. (www.bi.go.id). Kinerja karyawan suatu perusahaan di bidang perbankan dalam hal ini khususnya kinerja karyawan bagian kliring menjadi hal yang sangat penting untuk dilihat, kinerja karyawan yang baik akan menunjukan bahwa sebuah perusahaan tersebut memiliki tingkat kinerja yang baik pula. Dengan volume rata-rata harian lebih dari 300.000 lembar transaksi menunjukan bahwa kliring sangat membutuhkan kecepatan dalam dunia pemasaran jauh lebih cepat dari pada waktu yang dibutuhkan guna melengkapi pelaksanaan suatu aset transaksi dan kliring berperan sangat penting bagi aktivitas dan pendapatan di suatu bank. Hasil yang didapat ini merupakan peninjauan yang harus dilihat, bahwa masih banyak kelemahan dan kekurarngan. terutama dalam dunia perbankan. Agar bisa memberikan contoh yang baik, maka perlu dipelajari dan dinalisa faktor-faktor dari keberhasilan dan kekurangan tersebut.

Perkembamgan Sumber Daya Manusia ini mengakibatkan, semua perusahaan bersaing untuk menunjukan serta menaikan tingkat kinerja mereka. Sumber Daya Manusia juga merupakan peran penting yang dapat menentukan keberhasilan suatu organisasi. Suatu organisasi harus memiliki nilai lebih dibandingkan dengan organisasi lainnya. Kinerja individu suatu karyawan memiliki dua faktor yaitu faktor internal dan faktor eksternal. Faktor internal muncul dari dalam diri yang dapat memungkinkan adanya motivasi untuk bekerja lebih baik. Faktor eksternal ini sendiri karena kurangnya sarana dan prasarana, kurangnya kemampuan menggunakan suatu fasilitas yang ada dan sebagainya pada perusahaan. Jumlah komputer yang disediakan dalam perusahaan dapat mempengaruhi tingkat efektivitas penggunaan sistem informasi karena semakin banyak komputer, semakin mudah dalam mengakses dan mengolah data.

Prawirosentoso (2008) mengatakan kinerja merupakan hasil kerja yang dapat dicapai oleh seseorang atau sekelompok orang dalam suatu organisasi sesuai dengan wewenang dan tanggung jawab masing-masing dalam rangka upaya mencapai tujuan organisasi yang bersangkutan secara legal, tidak melanggar hukum, dan sesuai dengan moral maupun etika. Muslim A. Djalil et al., mengatakan tata kelola organisai yang baik (good governance), organisasi pemerintah diharapkan dapat mewujudkan akuntabilitas yang merupakan pondasi dari proses pemerintahan. Memberikan pelayanan yang baik, mengelola keuangan dengan baik dan mempertanggungjawabkan dana yang terhimpun merupakan perwujudan akuntabilitas pemerintahan. Dengan pernyataan tersebut bahwa karyawan memegang peranan penting dalam segala aktivitas perusahaan agar dapat tumbuh dan berkembang mempertahankan kelangsungan hidup perusahaan. Untuk menciptakan sumber daya manusia yang handal membutuhkan pengelolaan yang baik agar kinerja karyawan lebih optimal.

Karyawan dapat memotivasi diri sendiri untuk dapat lebih tekun dalam menyelesaikan pekerjaan, dan karyawan memiliki kepercayaan terhadap sistem informasi akuntansi dapat menyelesaikan pekerjaannya. Pada dasarnya suatu perusahaan bergerak di bidang perdagangan maupun jasa di sektor manufaktur memiliki tujuan yang sama yaitu untuk memperoleh laba dan menjaga kesinambungan perusahaan dimasa yang akan datang. Dalam menghadapi era globalisasi dan pasar bebas saat ini setiap perusahaan dihadapkan pada situasi lingkungan bisnis yang semakin tidak pasti dan persaingan yang semakin ketat untuk menjadi yang terbaik dalam bisnisnya. Dalam menghadapi persaingan tersebut, perusahaan dituntut untuk meningkatkan kinerja perusahaan. Kinerja karyawan sangat penting bagi suatu perusahaan sebagai suatu alat ukur keberhasilan dalam menjalankan usaha. Karena semakin tinggi kinerja karyawan, maka produktivitas dari perusahaan juga semakin tinggi.

BRI merupakan salah satu Bank BUMN dengan tingkat kinerja karyawan yang cukup baik, BRI menggunakan KPI dalam penggunaan mengukur kinerja karyawan, dan BRI akan memberi target pada 
karyawan dalam pengukuran kinerja. BRI salah satu perusahaan di bidang perbankan yang menjalankan program Sistem Informasi Akutansi. Pada akhir tahun 2017 BRI mengalami penurunan kinerja pegawainya serta keamanan sistem informasi, dalam berita tribunnews.com diketahui bahwa beberapa nasabah kehilangan dana dari buku tabungan mereka sendiri di karenakan adanya skimming atau kebocoran informasi nasabah. Dampak dari masalah ini adalah penurunan kepercayaan nasabah terhadap BRI, beberapa media mengatakan bahwa faktor terjadinya skimming adalah lemahnya keamanan Sistem Informsi yang di buat oleh BRI sehingga pelaku tersebut dapat mengduplikat data keuangan, data pribadi dan PIN yang mereka punya. Fenomena tersebut merupakan alasan peneliti untuk melakukan penelitian ini.

\section{Kajian Teori dan Pengembangan Hipotesis Stakeholder Theory}

Stakeholder theory merupakan kumpulan kebijakan dan praktik yang berhubungan dengan stakeholder, nilai-nilai, dan pemenuhan ketentuan hukum, penghargaan dan lingkungan, serta komitmen dunia usaha untuk berkontribusi dalam sebuah pembangunan secara berkelanjutan. Tarigan (2014) menyatakan stakeholder dibagi dalam dua kategori, yaitu:

1) Inside stakeholder, terdiri atas orang-orang yang mempunyai kepentingan dan tuntutan terhadap sumber daya perusahaan serta berada didalam organisasi perusahaan. Pihak-pihak yang termasuk dalam kategori inside stakeholder ini adalah pemegang saham (stockholder), manajer, dan karyawan.

2) Outside stakeholder, terdiri atas orang-orang maupun pihak-pihak yang bukan pemilik perusahaan, bukan pemimpin perusahaan, serta bukan pula karyawan perusahaan, namun memiliki kepentingan terhadap perusahaan yang dipengaruhi oleh keputusan serta tindakan yang dilakukan oleh perusahaan. Pihakpihak yang termasuk dalam kategori outside stakeholder ini adalah pelanggan (costumer), pemasok (supplier), pemerintah, masyarakat lokal, dan masyarakat umum. Perusahaan tidak hanya beroperasi untuk pribadi, namun harus dapat memberikan sesuatu untuk stakeholder- nya (pemegang saham, kreditor, konsumen, supplier, pemerintah, masyarakat, analis, dan pihak lain). Dengan demikian, keberadaan suatu perusahaan sangatlah dipengaruhi oleh dukungan yang diberikan oleh stakeholder.

Kinerja Karyawan yang baik dan pelayanan yang maksimal terhadap nasabah merupakan strategi perusahaan untuk memenuhi keinginan para stakeholder, semakin baik kinerja yang dilakukan karyawan perusahaan maka para stakeholder juga akan makin memberikan dukungan penuh kepada perusahaan atas segala aktivitasnya yang bertujuan untuk meningkatkan kinerja perusahaan dan mencapai laba.

\section{Kinerja Pekerja}

Kinerja karyawan adalah suatu hasil kerja yang secara kualitas dan kuantitas yang dicapai oleh seorang karyawan dalam melakukan tugasnya sesuai dengan tanggung jawab yang diberikan. Kinerja merupakan gabungan dari kemampuan seorang pekerja, dan penerimaan atas penjelasan suatu uraian tugas serta peranan dan tingkat motivasi seorang karyawan (Mangkunergara, 2000).

Prawirosentoso (2008) menyatakan bahwa kinerja adalah hasil kerja yang dapat dicapai oleh seseorang atau kelompok dalam suatu organisasi sesuai dengan wewenang dan tanggung jawab masing-masing dalam rangka upaya mencapai tujuan organisasi bersangkutan secara legal, tidak melanggar hukum dan sesuai dengan moral maupun etika. Kinerja mengacu pada prestasi karyawan yang diukur berdasarkan standar atau kreteria yang ditetapkan perusahaan. Pengertian kinerja atau prestasi kerja diberi batasan oleh As ad (2008) "sebagai kesuksessan seseorang didalam melaksanakan suatu pekerjaan. Kinerja adalah succesfull role achievement yang diperoleh seseorang dari perbuatan-perbuatannya. Kinerja merupakan hasil yang dicapai seseorang menurut ukuran yang berlaku untuk pekerjaan yang bersangkutan".

\section{Sistem Informasi Akuntansi}

Organisasi pada era saat ini sangat bergantung pada sistem informasi untuk mempertahankan hidupnya bahkan untuk mendapatkan keunggulan kompetitif. Informasi dapatlah dikatakan juga sebagai sumber daya, seperti gedung dan peralatan. Akuntansi 
merupakan sebuah sistem informasi menidentifikasi, mengukur dan mengkomunikasikan informasi tersebut kepada orang yang berkepentingan terhadap informasi.

Sistem informasi akuntansi menurut Bodnar dan Hopwood (2003) adalah kumpulan sumber daya, seperti manusia dan peralatan, yang dirancang untuk mengubah data keuangan dan data lainnya menjadi informasi yang akan dikomunikassikan kepada berbagai pihak pengambil keputusan. Menurut Chusing dalam Hall (2001) mendefinisikan sistem informasi akuntansi sebagai kumpulan dari manusia dan sumber-sumber daya modal di dalam suatu organisasi yang bertanggung jawab untuk menyediakan informasi keuangan dan juga informasi yang didapat dari pengumpulan dan pengolahan data transaksi.

Bodnar, George H dan William S. Hopwood (2015:8) menyebutkan "sistem informasi akuntansi adalah sistem berbasis komputer yang dirancang untuk mentransformasikan data akuntansi menjadi informasi". Pada dasarnya sistem informasi akuntansi yang disajikan dalam bentuk laporan keuangan digunakan sebagai dasar pembuatan keputusan yang menyangkut aspek keuangan dan non-keuangan dalam perusahaan.

\section{Metode Penelitian}

\section{Lokasi Dan Objek Studi}

Studi ini dilaksanakan dinatara satf wilayah BRI dan Banda Aceh. sedangkan variabel yakni pengguna sistem informasi untuk akuntansi dan produktivitas pekerja.

\section{Populasi Dan Sampel}

Populasi dalam penelitian yakni seluruh pegawai tetap BRI di Kota bnada Aceh yang bekerja di cabang BRI dan kantor wilayah yakni 105 orang.
Sedangkan sampel menggunakan metode pengambilan yang ditargetkan yaitu: (1) pekerja di kantor BRI cabang dan BRI wilayah di banda aceh sehingga sampel sebanyak 85 pekerja tetap.

\section{Metode Analisis dan Rancangan Pengujian Uji Validitas dan Reliabilitas}

Validitas menunjukkan ketepatan atau tingkat akurasi alat pengukur dalam mengukur data yang ingin diukur.

Uji reliabilitas dapat mengukur konsistensi alat ukur dalam mengukur suatu konsistensi responden dalam menjawab item pertanyaan dalam kuesioner atau instrumen penelitian.

\section{Uji Hipotesis}

$$
\mathbf{Y}=\mathbf{a}+\mathbf{b X}
$$

Keterangan:

$\mathrm{Y}=$ Variabel dependen (nilai yang diprediksi)

$\mathrm{X}=$ Variabel independen

$\mathrm{a}=$ Konstanta (nilai $\mathrm{Y}^{\prime}$ apabila $\mathrm{X}=0$ )

$\mathrm{b}=$ Koefisien regresi (nilai peningkatan ataupun penurunan

H1: Penerapan Sistem Informasi Akutansi berpengaruh terhadap Kinerja Karyawan BRI Cabang Banda Aceh.

\section{Hasil dan Pembahasan}

Responden dalam penelitian ini sebanyak 85 responden karyawan pada Bank BRI Cabang dan Wilayah Banda Aceh. Kuesioner yang diedarkan untuk pengumpulan data sebanyak 85 eksemplar. Karakteristik responden dalam penelitian ini merupakan ciri-ciri responden terutama mengenai jenis kelamin, usia, pendidikan, dan masa kerja di BRI Cabang dan Wilayah Banda Aceh. Lebih lanjut dapat dilihat pada tabel 4.1.

\begin{tabular}{|c|l|l|l|}
\hline No & Uraian & Frekuensi(orang) & Persentase (\%) \\
\hline $\mathbf{1}$ & Jenis Kelamin & & \\
& Laki-laki & 47 & $55,3 \%$ \\
& Perempuan & 38 & $44,7 \%$ \\
\hline \multicolumn{2}{|c|}{ Jumlah } & $\mathbf{8 5}$ & $\mathbf{1 0 0} \%$ \\
\hline $\mathbf{2}$ & Usia & & \\
& 21-30 Tahun & 41 & $48,2 \%$ \\
& $31-40$ Tahun & 35 & $41.2 \%$ \\
& Di atas 40 Tahun & 9 & $10,6 \%$ \\
\hline \multicolumn{2}{|c|}{ Jumlah } & $\mathbf{8 5}$ & $\mathbf{1 0 0} \%$ \\
\hline
\end{tabular}




\begin{tabular}{|c|c|c|c|}
\hline 3 & $\begin{array}{l}\text { Pendidikan } \\
\text { SLTA atau Setingkat Sarjana } \\
\text { Muda (D3)/ DII atau Sederajat } \\
\text { Sarjana (S1) Pascasarjana }\end{array}$ & $\begin{array}{l}1 \\
12 \\
70 \\
2\end{array}$ & $\begin{array}{l}1,2 \% \\
14,1 \% \\
82,4 \% \\
2,4 \%\end{array}$ \\
\hline \multicolumn{2}{|c|}{ Jumlah } & 85 & $100 \%$ \\
\hline 4 & $\begin{array}{l}\text { Masa Kerja } \\
\text { 1-2 Tahun } \\
\text { 3-5 Ttahun } \\
\text { 6-15 Tahun } \\
\text { Di atas } 15 \text { Tahun }\end{array}$ & $\begin{array}{l}12 \\
33 \\
33 \\
7\end{array}$ & $\begin{array}{l}14,1 \% \\
38,8 \% \\
38,8 \% \\
8,2 \%\end{array}$ \\
\hline \multicolumn{2}{|c|}{ Jumlah } & 85 & $100 \%$ \\
\hline
\end{tabular}

\section{Hasil Pengujian Validitas dan Reliabilitas}

\section{Hasil Uji Validitas}

Dari hasil penelitian menunjukkan bahwa semua item yang terlibat dalam penelitian menunjukkan korelasi yang baik sehingga dapat menjadi suatu pengukuran yang tepat. Hal ini dilihat dari nilai memiliki interval 0,628 hingga 0.750 .

\section{Hasil Uji Reliabilitas}

Uji ini hanya dilakukan satu kali pada sekelompok responden masing- masing variabel.

Ukuran

\section{Tabel 4.5 Hasil Uji Reliability}

reliabilitas dianggap handal berdasarkan pada koefisien alpha 0,60 (Malholtra, 2012).

\begin{tabular}{|c|l|c|c|c|c|}
\hline \multirow{2}{*}{ No } & \multirow{2}{*}{ Variabel } & \multirow{2}{*}{$\begin{array}{c}\text { Jumlah } \\
\text { Item }\end{array}$} & \multicolumn{2}{|c|}{ Cronbach's Alpha } & \multirow{2}{*}{ Keterangan } \\
\cline { 4 - 5 } & & Hitun g & Standar & \\
\hline 1 & Sistem Informasi Akuntansi & 6 & 0,678 & 0,60 & Reabel \\
\hline 2 & Kinerja Karyawan & 6 & 0,726 & 0,60 & Reabel \\
\hline
\end{tabular}

Sumber: Data diolah, 2019

\section{Uji Asumsi Klasik}

\section{Uji Normalitas}

One-Sample Kolmogorov-Smirnov Test

\begin{tabular}{|c|c|c|}
\hline & & $\begin{array}{c}\text { Unstandardized } \\
\text { Residual }\end{array}$ \\
\hline $\mathrm{N}$ & & 85 \\
\hline Normal Parameters ${ }^{\mathrm{a}, \mathrm{b}}$ & $\begin{array}{l}\text { Mean } \\
\text { Std. } \\
\text { Deviatio } \\
\mathrm{n}\end{array}$ & $\begin{array}{r}, 0000000 \\
2,57110648\end{array}$ \\
\hline $\begin{array}{l}\text { Most Extreme Differences } \\
\text { Test Statistic }\end{array}$ & $\begin{array}{l}\text { Absolute } \\
\text { Positive } \\
\text { Negative }\end{array}$ & $\begin{array}{r}, 141 \\
, 074 \\
-, 141 \\
, 141\end{array}$ \\
\hline Asymp. Sig. (2-tailed) & &, $000^{c}$ \\
\hline
\end{tabular}

a. Test distribution is

Normal. b. Calculated from data.
Hasil Metode Analisis Regresi Linear Berganda

Tabel 4.11

Analisis Pengaruh Sistem Informasi Akuntansi terhadap Kinerja Karyawan

\begin{tabular}{|c|c|c|c|c|c|c|}
\hline \multicolumn{7}{|c|}{ Coefficients $^{\mathrm{z}}$} \\
\hline \multirow{2}{*}{\multicolumn{2}{|c|}{ Model }} & \multicolumn{2}{|c|}{ Unstandardized Coefficients } & Standardized & & \\
\hline & & B & Std. Error & Beta & $t$ & Sig. \\
\hline \multirow[t]{2}{*}{1} & (Constant) & 18,299 & 2,968 & & 6,165 & .000 \\
\hline & akuntansi & .226 & .119 & 205 & 1,905 & .060 \\
\hline
\end{tabular}

Maka dari persamaan tersebut dapat dijelaskan bahwa koefisien regresi Sistem Informasi Akuntansi (X) bernilai positif $(0,205)$ artinya ketika SIA dapat berjalan lancar dalam sebuah perusahaan maka akan dapat meningkatkan Kinerja karyawan pula tersebut. Selain menguji koefisien regresi, penelitian ini juga menguji koefisien korelasi (R) dan koefisien 
determinasi (R2). Koefisien korelasi bertujuan untuk melihat keeratan hubungan antara satu variabel dengan variabel lainnya. Koefisien korelasi (R) positif kuat apabila hasil korelasi mendekati +1 atau sama dengan +1 . Korelasi negatif kuat apabila hasil korelasi mendekati -1 atau sama dengan -1 .

Tidak ada korelasi apabila hasil korelasi mendekati 0 atau sama dengan 0 . Jika korelasi bernilai +1 atau -1 maka variabelnya menunjukkan korelasi sempurna positif atau negatif. Sementara koefisien determinan (R2) mengukur seberapa jauh kemampuan variabelvariabel independen dalam menjelaskan variasi variabel dependen (Ghozali, 2001).

\section{Kesimpulan dan Saran Kesimpulan}

SIA berpengaruh positif kepada kinerja pekerja pada BRI Cabang dan Wilayah Banda Aceh. bisa dikatkan bahwasannya SIA sangat membantu beberapa pekerjaan dan SIA di Bank saat ini cukup positif pada menakar kinerja. Sudah terbukti pada studi SIA mevalue bahwasnnya kinerja pekerja bisa dievaluasi dari sebuah program.

\section{Saran}

Berdasarkan hasil studi yang telah didapat, para pekerja cabang dan wilayah banda aceh. hal ini tentunya wajib diperhatikan, karena level kinerja pekerja sangat positif di BRI Cabang dan Wilayah Banda Aceh, perusahaan wajib selalu menjaga level kinerja pekerja dengan memberi pelatihan kepada pekerja pada kegunaa SIA pada perusahaan.

\section{Daftar Pustaka}

Sekaran, Uma dan Roger Bougie. (2017). Metode Penelitian untuk Bisnis Pendekatan Pengembangan-Keahlian. Edisi 6. Buku 1. Jakarta: Salemba Empat.

As ad. Moh. 2008. Psikologi Industri. Yogyakarta: Leberty.

Bodnar, George H dan William S. Wopwood, 2006. Sistem Informasi Akuntansi (Edisi 9). Yogyakarta. Penerbit Andi. Gefen, D., Karahanna, E., Straub, D.W., 2003. Trust and TAM in online shopping: an integrated model. MIS Q. 27 (1), 51-90.

Ferran C, Salim R (2011) IAC accounting data model: a better data structure for computerized accounting systems. Rev Bus Info Syst 8: 109-120.

Muslim A Djalil, et al. 2017. The Influence of Usefulness, Adequacy of Information, and Perceived Risk of Electronic Money Brizzi Adoption in Banda Aceh - Indonesia. Journal of Accounting.

Prawirosentoso, Suryadi. 2008. Manajemen Sumber Daya Manusia Kebijakan Kinerja Karyawan. Yogyakarta: BPFE.

Saira K, Zariyawati MA, Annuar MN (2010) Information system and firms performance: The Case of Malaysian small medium enterprises. Int Bus Res 3: 28-35.

Saputri. 2015. Metode Penelitian Sosial \& Bisnis. Jakarta: Graha Ilmu.

Sekaran, Uma dan Roger Bougie. (2017). Metode Penelitian untuk Bisnis Pendekatan Pengembangan-Keahlian. Edisi 6. Buku 2. Jakarta: Salemba Empat.

Prawirosentoso, Suryadi. 2008. Manajemen Sumber Daya Manusia Kebijakan Kinerja Karyawan. Yogyakarta: BPFE.

Tarigan, Josua dan Hantane Samuel. 2014. Pengungkapan Sustainability Report dan Kinerja Keuangan. Jurnal Akuntansi dan Keuangan Universitas Kristen Petra.Vol. 16, No. 2, November 2014, hal 88-101. 